JEA

60,1

118

\title{
Commentary - Research on
successful school principalship:
progress on a secure front \\ Commentary - Research on
successful school principalship:
progress on a secure front \\ Commentary - Research on
successful school principalship:
progress on a secure front
}

The warrant

In a special issue of this journal devoted to International Successful School Principalship Project (ISSPP) members' research, Ken Leithwood, a founding member, commented that four years after its foundation in 2001, there had been "progress on a broken front" (Leithwood, 2005). He meant that, at that time, not enough cases had been produced to make conceptually robust generalisable, research-informed claims about the contributions to the knowledge of successful school principalship by ISSPP researchers. In the 15 plus years since then, this situation has been reversed. The number of countries and researchers has grown considerably during that period, and, as the papers included in this special issue show, so have the number of case studies on successful school principalship using a commonly agreed research design and instruments in a range of schools and countries, which have been produced and published. Judged by any standards, the sustained conduct of the research, some of which is reported in this special issue, is a remarkable achievement. The ISSPP has advanced conceptually, methodologically, in its understandings, and in the credibility of its claims for the conceptualisation, definition and practices of successful school principalship. So, the papers in this issue enable us to take a deeper dive into the ISSPP's contribution to knowledge over a much more common, "unbroken" front.

This special issue is unusual in several ways. First, six of the seven papers present syntheses of ISSPP members' research on successful leadership, carried out over more than a decade - and in some cases longer than this - in six different countries: Australia, Cyprus, Israel, Mexico, Spain and the USA. Whilst they do not claim to be representative of all the research carried out in this network of researchers in 24 countries, they illustrate three important features: First, it is possible for academics from different cultures in countries with different educational histories, in different phases of their development and working in different contexts to collaborate in designing multi-perspective, multi-level research protocols, translate these into the language of their own country and apply and sustain the application of such protocols to increase understandings of the complex work and worlds of successful principals in their own countries. Second, many of the papers illustrate researchers' persistent pursuit of knowledge, which is driven partly by their commitment to social justice, within contexts of key social and economic challenges of equity and inclusion. The part played by researcher values in the choice, focus and conduct of research in the educational leadership field remains a relatively under-explored area. Researcher reform commitments are most clearly seen in the extensive Mexican, Spanish and USA research, which has focussed primarily on principals who work in schools that serve highly disadvantaged, conflicted communities. Third, the research identifies that successful principals who work in diverse contexts and speak in different languages hold common values and initiate similar practices. Diversity exists in the differences between the cultural contexts of the countries and the structure and governance of the school systems in which the principals work. For example, Australia has three school systems (state, Catholic and independent), whereas others do not; Cyprus has a bureaucratic system of promotion to principal; Spain until recently had a system of principals who have been elected from within the school for a set period. Diversity can be found, also, in the different foci of the research 
reported here. For example, in Mexico, Spain and the USA, the focus is on successful principals of schools serving disadvantaged communities, whereas this is not the case in Australia, Cyprus and Israel.

\section{The papers}

In a synthesis of 23 case studies, "Successful Principal Leadership in Challenging Public Schools", conducted in seven states in the USA, the authors report that successful principals in schools that serve high-need communities demonstrate a strong service ethic, commitment to equity, social justice and inclusion, are resilient, persistent and "stayers" over time in their schools as they grow success, despite the challenges. The authors characterise leadership as a "multi-level phenomenon influenced by internal and external networks of relationships". The research demonstrates the importance of principal stability in schools, especially those that serve high-need, often impoverished and divided communities, but shows that lasting success can be achieved even in the most challenging of circumstances. The findings challenge so-called "cause and effect" notions that functionally oriented policies, adverse home and community conditions necessarily result in school failure.

Similar to the USA, "Successful school leadership for social justice in Spain" presents a synthesis of the findings from 12 Spanish case studies, finding that successful principals are those who can manage the uncertainties of changing government policies and challenge the ever-present social inequalities. These successful principals had a strong social justice orientation, using a combination of "transformational" and "instructional" practices to engage their internal and external school communities. Like the USA, the principals demonstrated strong personal/professional qualities of empathy, openness to dialogue, positive emotions and collaborative leadership.

The paper entitled "What we know about successful principals in Mexico" analyses documents about 14 ISSPP schools across the country. Like the research reported from Spain and the USA, the focus in Mexico is upon issues of equity and social justice. Within this, there is a clear focus upon how success has been achieved through a leadership emphasis by the principals upon personal, social and emotional development, as they use a range of personal and professional qualities and skills to "build human beings" through close relationships with parents, including home visits.

"Successful School Principals in Primary and Secondary Education: A Comprehensive Review of a 10 year research project in Cyprus" is a cross-case re-analysis of 11 case studies that identifies the importance of both internal and external dimensions of the work of successful principals. Their focus was on developing external relations, networking, collaboration and shared ownership, though there was more evidence of the latter in primary than secondary schools. As with the other papers, the authors found that no singular "adjectival" model of success could be identified or easily transferred across school and system-level contexts. The analysis illustrates, as with the other papers, that whilst differences in cultural and policy contexts count, for example, the importance of parental involvement in a Cypriot culture in which familial values remain strong, successful principals across the school sectors seem to hold the same educational values and engage in similar strategies and actions. This is perhaps an indirect "nudge" for ISSPP members to undertake more research in its Strand 3 research, which focusses on principal identities. The paper also contains a simplified "model" of successful school principalship in the centralised school system in Cyprus.

"Successful, coasting, and low-performing schoolprincipals in Israel: An explanatory model" synthesises 21 case studies, in presenting a "cyclic causality explanation", of successful principals' values as demonstrated in the organisational structure of schools, their infrastructures, cultures and, especially, routines and regularities. In Israel, as in other countries, 
JEA

60,1 the successful principal is "the key player who turns the wheel". The authors also compare successful with less successful principals.

The Australian paper, "An open systems model of successful school leadership", builds upon 13 published models of successful principalship, developed over the previous 12 years. Its authors develop a 14th generic, "open systems," explanatory model of the contexts, influences, characteristics and elements of successful principalship. The model indicates that "success in a school leadership context is a process of mutual influence", that successful leadership is "context sensitive but not context driven" and that successful principals demonstrate "contextual intelligence" and the ability to engage in "adaptive change". As the authors note, "a model is an abstraction of reality and a simplified representation of a real-world phenomenon" (Robbins et al., 2016, p. 17). Such simplified representations of researcher understandings of successful school leadership are very useful as essentially explanatory devices, which stimulate and encourage further thought and discussion. Their limitation is that they cannot easily map the intersections, dynamic relations and complex interactions within and between the key identifiers in as precise a way as, for example, structural equation modelling can do. Because the former tend to be the result of qualitatively informed judgements and the latter the result of quantitative analyses only, neither can fully represent the degree to which one aspect of "reality" influences and is influenced by another or combinations of others.

\section{Positioning success in school principalship and the importance of agency} Why "success" is different from "effectiveness" in school principalship

Conceptually and empirically informed robust models, such as those in the papers in this issue, reinforce the range of ISSPP research findings across more than 20 countries of successful principals in different cultural contexts and in primary and secondary schools that serve a range of communities. Although contexts count, and successful principals are culturally responsive, the research reported in this issue and elsewhere has found that values and principles of successful principals are similar, and that their strategies, emphasis on the quality of interpersonal relations, leadership distribution, capacity building, well-being and academic achievement and focus upon building and sustaining high levels of trust between staff, staff and students, staff and community beyond the school gates, awareness and mediation of internal and external contexts and needs, though carried through in different contextually relevant and culturally sensitive ways and times, are common. Essentially, the papers in this issue endorse the view based on early ISSPP research that

Success includes, but is more than, effectiveness. Whereas the latter (associated with observable behaviors and outcomes which are quantifiable), is always part of the former, the former is not necessarily a part of the latter. In general, we may say that "effectiveness" is associated with instrumental outcomes of students (tests, examination results), whereas success is associated with these in addition to positive personal and social outcomes, well-being, and equity. In others words, success is more all encompassing, more complex to discern than the sets of bullet points, good advice, and other indicators so readily available from the plethora of school effectiveness research, policy documents, and training and development program documentation (Day, 2007, p. 15)

If this is the case, then it signals the demise of research reports on principals in general, which fail to make clear the now empirically well-supported differences between "principal leadership", "effective" principal leadership and "successful" principal leadership.

\section{Relationships between structure and agency}

It is clear that successful principals in ISSPP research take key initiating and mediating roles within and without the school in building and sustaining success. In doing so, they exercise a high degree of agency within structures, which implicitly seek compliance. Agency has been defined as being exercised in particular "when professional subjects and/or communities exert 
influence, make choice, and take stances on their work and/or professional identities" (Etelapelto et al., 2013, pp. 57-8).

Despite the challenge of external policies, which are claimed by many academics to reduce schools' opportunities for decision-making about the purposes, contents and pedagogical features of education, and the special features of the communities which their schools serve, these successful principals succeed in establishing and sustaining a broad-based rather than functionally oriented education. In short, educational values and practices in the schools which they lead are influenced but not determined by external forces. These principals and staff enact rather than implement. In short, they exercise a high degree of personal and positional agency.

The Norwegian paper in this issue, entitled "Looking back and forward: A critical review of the history and future progress of ISSPP", is of particular interest in relation to this, in the call which its authors make for more attention to be given by researchers to critically analyse who successful principals are and what they do, in the "the wider power structures of school leadership". Whilst this has been a recurring message in academic papers over many years in relation to critiques of policy developments in education in general, it remains an important issue for those who research school leaders, in general, and school principals, in particular. There are ongoing debates internationally about the influence and effects of neoliberal policies on, in this case, education. Schools have been characterised as being populated by "regimes of numbers" which have become "a resource through which surveillance can be exercised", and "data [have] become the resource for comparison" (Ozga, 2008, p. 264). Others have suggested that the discourse of "occupational professionalism" in which teachers have been able to exercise levels of discretionary judgements about the content, pace and direction of their work has been replaced by forms of "managerial professionalism" in which individual choice has become more limited (Evetts, 2013). According to these perspectives, education is increasingly enacted through largely functional measures and targets against which schools must position themselves, such that, "The self-managing individual and autonomous organisations are produced within the intricacies of performativity through audits, inspections, appraisals, self-reviews, quality assurance" (Ball, 2012, p. 31).

The debate is extensive, on-going and important, since it reaches to the heart of educational purposes. The ISSPP research is framed within this context. However, what it has found is that, whilst this is undoubtedly the context in which many schools in many countries find themselves, the challenges which it brings influence but do not necessarily determine what happens within them. The findings from ISSPP research clearly demonstrate that successful school principals have, exercise and communicate a powerful sense of agency throughout their schools and communities.

Its multi-perspective, multi-level design enables its members to go beyond what the authors of the Norwegian paper describe as "an understanding of practice as action" in focussing their research, regardless of context, on the dynamic interplay between both external influences, internal school structures, cultures and actions and principal "agency", defined as the "powerful belief that social and organisational structures and cultures, rather than simply tolerated, can be influenced by individual and collective action" (Day, 2017, p. 36).

This is another important key feature which distinguishes "successful principalship from "effective' principalship" and "principalship" in general. Its findings of the effects of "performativity" agendas are also different. They present data which provide a clear alternative view to the "compliancy" assertions by others of the extent to which external power and structures necessarily create principals and teachers who are unable to assert their professionalism and use their "professional capital" (Hargreaves and Fullan, 2015).

Far from being the victims of systems which privilege "performativity", principals and teachers in successful schools are able to mobilise their educational beliefs, values, purposes 
JEA

60,1

and practices to assert broader moral purposes associated with, for example, attention to the personal and social education of their students (Biesta and Tedder, 2007).

In short, successful principals continue to be revealed as having a commitment to care for the broader well-being and attitudinal as well as the narrower, functional education of the students in the school and the courage and resilience to put this broader agenda into practice through the structures, cultures, relationship and routines and regularities which, indirectly and directly, they establish in the schools which they lead. ISSPP research findings do not dispute that the environments in which principals and their teachers work are challenging, for all the reasons provided in debates about power, structures and Foucauldian notions of "regimes of truth" (Hall and Noyes, 2009). Indeed, contexts are described fully in almost all ISSPP case studies. However, it is the case that these successful principals have been able to find ways of mediating, mitigating and moving beyond compliancy. Thus, the case studies in this issue, among others by members of the ISSPP network, draw attention not only to the broader social and policy contexts in which principals lead but also how they build and achieve success within and beyond them.

\section{Moving forward}

As I write this, the ISSPP has reached another milestone in its journey as a research network. For the last two years, we have been reviewing our own research questions, methodology and research instruments in relation to our purposes and aspirations. As a result, we have now anchored our work more explicitly in complexity theory (appropriate to our findings of the complexity of successful principalship), we have updated our research protocols, taking what our members and others have discovered about successful principalship over the last 20 years, and we have developed a new analytical framework, which underpins our research. We have re-designed a school staff survey, enabling all our research to be mixed methods and thus strengthen its empirical warrant. We have ensured that all aspects of our research going forward are related to our revised theoretical stance and core research questions. In doing so, we will go deeper in our work to demonstrate a new conceptual and methodological rigour. In addition, we will be able to adhere more precisely to the principles and practices of the best comparative research. Ongoing, we are conducting a meta-analysis of our past publications, selected using clear quality assured criteria. We will use the results to inform ourselves and others further of the collective results of our research. The ISSPP network will continue its tradition of being open to more and less experienced scholars drawn from all regions of the world and mount "Research and Practice" conferences to reach out to principals themselves. Finally, we will build further on our website, the wide range of publications in refereed journals internationally, books and book chapters, and conference contributions. Like successful school principals, we will continue to be passionate in what we do, robust and rigorous in how we do it and always look forward.

Christopher W. Day School of Education, University of Nottingham, Nottingham, UK

\section{References}

Ball, S.J. (2012), Politics and Policy Making in Education: Explorations in Sociology, Routledge, London.

Biesta, G. and Tedder, M. (2007), "Agency and learning in the lifecourse: towards an ecological perspective", Studies in the Education of Adults, Vol. 39 No. 2, pp. 132-149.

Day, C. (2007), What being a successful principal really means: an international perspective, Educational Leadership and Administration, Fall, Vol. 19, pp. 13-24. 
Day, C. (2017), Teachers' Worlds and Work: Understanding Complexity, Building Quality, Routledge, London.

Eteläpelto, A., Vähäsantanen, K., Hökkä, P. and Paloniemi, S. (2013), "What is agency? Conceptualizing professional agency at work", Educational Research Review, Vol. 10, pp. 45-65.

Evetts, J. (2013), "Professionalism: value and ideology”, Current Sociology, Vol. 61 Nos 5-6, pp. 778-796.

Hall, C. and Noyes, A. (2009), "New regimes of truth: the impact of performative school self evaluation systems on teachers' professional identities", Teaching and Teacher Education, Vol. 25 No. 6, pp. 850-856.

Hargreaves, A. and Fullan, M. (2015), Professional Capital: Transformng Teaching in Every School, Teachers College Press, New York.

Leithwood, K. (2005), "Understanding successful principal leadership: progress on a broken front", Journal of Educational Administration, Vol. 43 No. 6, pp. 619-629.

Ozga, J. (2008), “Governing knowledge: research steering and research quality”, European Educational Research Journal, Vol. 7 No. 3, pp. 261-272.

Robbins, S., Judge, T., Millett, B. and Boyle, M. (2016), Organisational Behaviour, Pearson Australia, Sydney.

\section{Further reading}

Day, C. and Leithwood, K. (Eds) (2007), Successful Principal Leadership in Times of Change: an International Perspective, Springer Science \& Business Media, Dordrecht, Vol. 5. 